Crime, Histoire \& Sociétés / Crime, History \& Societies

Vol. 21, n² | 2017

L'histoire de la criminalité et de la justice pénale : propositions de recherche pour le $21^{\mathrm{e}}$ siècle

\title{
Criminologists and Historians of Crime: A Partnership Well Worth Pursuing
}

\section{Randolph Roth}

\section{(2) OpenEdition \\ Journals}

Electronic version

URL: http://journals.openedition.org/chs/2064

DOI: $10.4000 /$ chs.2064

ISSN: 1663-4837

\section{Publisher}

Librairie Droz

\section{Printed version}

Date of publication: 31 December 2017

Number of pages: 387-399

ISSN: $1422-0857$

\section{Electronic reference}

Randolph Roth, "Criminologists and Historians of Crime: A Partnership Well Worth Pursuing", Crime, Histoire \& Sociétés / Crime, History \& Societies [Online], Vol. 21, n² | 2017, Online since 19 July 2020, connection on 14 January 2021. URL: http://journals.openedition.org/chs/2064 ; DOI: https://doi.org/ $10.4000 /$ chs.2064 


\title{
Criminologists and Historians of Crime: A Partnership Well Worth Pursuing
}

\author{
Randolph Roth ${ }^{1}$
}

Grom 2013 to 2016, I had the privilege of serving as a member of the National F Academy of Science's Roundtable on Crime Trends. The Roundtable, sponsored by the National Institute of Justice, brought together scholars from criminology, public health, economics, and sociology, as well as jurists, public health officials, and former police chiefs, in an effort to better understand recent trends in street crime in the United States, particularly the so-called "crime drop" of the 1990s. Ably chaired by eminent criminologist Richard Rosenfeld, the Roundtable read widely, heard presentations from experts on a host of topics (from trends in youth behavior to the likelihood of recidivism), and sorted through rival theories (such as the lead hypothesis and the emergency care hypothesis). By the rules of the NAS, we were not allowed as a "roundtable" to come to any conclusions as a group or to issue a final report, which is just as well, given that we disagreed to the very end about pretty much everything, including the existence of the alleged "crime drop" of the 1990s. But for me as a historian, it was a wonderful opportunity to work with and learn from some of the world's finest scholars and public servants. And yes, Doug Eckberg and I asked a kind tourist to take a picture of us in front of Einstein's statue at the NAS, just to prove we social science historians were there!

I found myself deeply impressed by the quality of the work that social scientists have done and are doing to understand crime trends and to identify interventions (such as hot spots policing) that may help save lives and deter crime in the future. But I also came away with an appreciation of how we as historians might contribute their efforts - in particular, how our research skills, the temporal depth of our knowledge, and our appreciation of the complexity of change could improve our understanding of contemporary crime trends.

1 Randolph Roth is Professor of History and Sociology at Ohio State University and co-founder and co-director of the Historical Violence Database, sponsored by the Criminal Justice Research Center at Ohio State (https://cjrc.osu.edu/research/interdisciplinary/hvd). He is a Fellow of the American Association for the Advancement of Science, and he has served as a member of the National Academy of Sciences Roundtable of Crime Trends (2013-2016) and the Board of Editors of the American Historical Review (2014-2017). He is the author of American Homicide (The Belknap Press of the Harvard University Press, 2009), which received the 2011 Michael J. Hindelang Award from American Societyof Criminology and the 2010 Allan Sharlin Memorial Prize from the Social Science History Association. He is currently completing Child Murder in America, a study of homicides of and by children from colonial times to the present. The author thanks the National Science Foundation, the Harry Frank Guggenheim Foundation, the National Endowment for the Humanities, and Ohio State University for their support. 


\section{BETTER DATA}

First and foremost, the data. Criminologists are well aware that the official data on homicides, police-involved shootings, etc., are deeply flawed ${ }^{2}$ Michael Maltz, for instance, has developed a sophisticated version in EXCEL of the FBI's Uniform Crime Reports, which since 1960 have tried to compile monthly or annual tallies of crimes known to law enforcement in the over 15,000 legal jurisdictions in the United States. The problem, as Maltz notes, is that some jurisdictions miss a month or two each year, some report erratically, and some not at all. Reporting is voluntary, and because the F.B.I. lacks the funds to gather the data itself, the gaps go unfilled. Maltz's database shows the gaps in reporting, which are considerable and nonrandom - but no one has yet tried to fill those gaps ${ }^{3}$.

In the midst of the homicide crisis of the 1960s, the FBI realized that it needed more than simple counts of homicides if it was to understand the surge in violence. It therefore developed a more comprehensive, complicated report for homicides. The Supplementary Homicide Reports - that is, supplementary to the UCRs - were introduced in 1968 and implemented nationwide in 1976 to gather rudimentary data on the particulars of homicides: the age, race, and gender of victims and suspects, the relationships between victims and suspects (strangers, relatives, intimate partners, etc.), and the basic motives for the homicides (e.g. "love triangle," "other argument"). The SHRs are a valuable resource to scholars and law enforcement, but because compliance was again voluntary and because no funds were allocated for local data entry or training, the reports are riddled with gaps and errors, and a number of jurisdictions simply threw up their hands and refused to fill out the lengthy forms. The SHRs do not include important categories of homicide, such as the homicides of law enforcement offices in the line of duty. And because the SHRs do not include the names of suspected victims of homicide - even though those names are a matter of public record throughout the United States - it is difficult to match the victims in the SHRs to victims in local databases and to correct errors in the data. Criminologists have tried to compensate for these gaps and errors statistically, by estimating through extrapolation the degree of underreporting ${ }^{4}$. But again, few have tried to determine from local records the extent of the gaps and errors.

Finally, the Bureau of Vital Statistics (now the National Center for Health Statistics) has tried since 1900 to gather information on mortality from state departments of health. Initially, only a handful of states met the Bureau's requirements for inclusion in the Death Registration Area, especially the requirement that data be gathered on the age, gender, race, and cause of death (including homicide) of at least 90 percent of all decedents. But since 1933, every state has met those requirements. Researchers have found that these mortality data offer the most complete counts of homicide, but they too are liable to underreporting, entry errors, and classification errors, which

Loftin and McDowall (2010); Logan et al. (2009); Loftin et al. (2008); Karch and Logan (2008); Shields and Ward (2008); Riedel and Regoeczi (2006); Van Court and Trent (2004); Azrael et al. (2001); Wiersema et al. (2000); Rokaw et al. (1990); and Zimring (2017).

3 See Maltz (1999. 2006). Maltz's UCR database can be accessed through the Historical Violence Database (HVD), sponsored by the Criminal Justice Research Center at Ohio State University: https:// cjrc.osu.edu/research/interdisciplinary/hvd/united-states/ucr.

4 See, for example, (Fox and Swatt 2009). 
increased when the International Code of Deaths were first adopted nationwide in 1959. The codes are numerous, and they have been updated and made more numerous through revisions in 1968, 1979, and 1999, with another revision pending. Perhaps the most fatal flaw in the system is the requirement that states report their "final" tallies of mortality to the NCHS within eighteen months of the end of each calendar year - an impossible burden for some local jurisdictions (especially large cities), particularly before the development of modern information systems in the 1990s. That means that the data available through the NCHS do not include deaths that were included or corrected by state departments of health after the eighteen month deadline. And because most state mortality records are confidential, researchers have not been able to create a comprehensive, public-use mortality database from the final counts.

The greatest problem, however, is that criminologists seldom engage in the historical research necessary to correct such flaws. No doubt, such research is difficult and time consuming, but an abundance of data from multiple sources has survived, which can be used to develop accurate counts. As my colleagues and I discovered in our National Homicide Data Improvement Project, 1959-present (a collaborative effort to improve the quality of homicide data funded by the National Science Foundation and the Harry Frank Guggenheim Foundation), coroner's records, mortality records, law enforcement records, and newspapers can be used together to build stronger databases. We have found that local medical examiners, police chiefs, sheriffs, and public health officials have been willing at every turn to help us gain access to the necessary records, with appropriate agreements to ensure the confidentiality of information that is not a matter of public record, such as the case files of homicides still under active investigation ${ }^{5}$.

Our pilot project, a clustered random sample of 34 counties in Ohio, has shown, as the title to our first conference paper shows, that "Whatever Can Go Wrong Does Go Wrong." Wendy Regoczi, Rania Issa, and I discovered in our co-authored paper that the ages of victims and suspects were transposed, that typos in geographical codes sent double homicides hurtling across the state, and that coding decisions by medical examiners inflated or deflated the number of "homicides" in a given county arbitrarily. For instance, Seneca County, a relatively non-violent county, suffered a rash of "homicides" in the 1970s, according to the Ohio Department of Health mortality records. Further investigation showed that five of the "homicides" were in fact accidents in which negligence led to deaths: two accidental deaths of children in a fire, two auto accidents, and an unusual accident when a street sign felled by a motorist crushed a child standing nearby. On the other hand, the ODH death records can conceal the number of homicides, as they did in Perry County. The death recorder classified three homicides as deaths from assaults of unknown intent, another homicide as a death from an unknown cause, and yet another homicide as a suicide. These errors reversed the homicide rates for Seneca and Perry counties - a disaster when it comes to studying the social geography of homicide in rural counties.

Another problem is to determine where the assault occurred. Mortality records indicate where a person died or where a body was found, and that can be misleading if a rural assault victim was transferred to an urban hospital, or if the body of an

My co-principal investigator is Wendy Regoeczi. Our co-investigators are Rania Issa, Michael Maltz, Douglas Eckberg, Roland Chilton, and Marc Riedel. Our graduate research assistants include Daniel Vandersommers, Megan Chew, Joe Wachtel, and Racheal Pesta. 
urban victim was dumped in a remote rural area, a fate that befell the victims of a serial killer of gay men in Indianapolis and Dayton, who dumped most of his victims in Preble County, Ohio, on the Indiana border. Further, few victims whose remains were found months or years after their deaths were included in the ODH mortality files (for reasons that are not yet clear), and if they were included in the SHRs, they appeared under the month and year in which their bodies were found rather than in the month and year they went missing - a tremendous puzzle for researchers, given the lack of victims' names in the SHRs.

Finally, death certificates must be updated at the end of homicide investigations. It is customary in some overburdened jurisdictions for coroners to issue provisional death certificates in homicide cases, with the cause of death listed as "unknown," so families can bury the dead and arrange their financial affairs. If those provisional certificates are not updated, however, or entered into a state's information system, those homicides will appear forever as deaths from "unknown" causes, lost among the many natural deaths in which the specific cause was never identified.

What is the bottom line? What percentage of homicides shows up in existing databases? Our research to date shows that when integrated, the SHRs and the ODH death records contain nearly a complete record of the estimated number of homicides that occurred in our sample counties - 95 percent or better 6 . But separately, they perform poorly, because of the failure of rural, suburban, and small town law enforcement agencies to submit SHRs on a regular basis, and because urban medical examiners and death reporters can be overwhelmed by the number of cases they need to report to the ODH. We discovered that from 1976-1988, only 322 of the estimated 578.7 homicides that occurred in the non-urban counties in our sample appeared in the SHRs - 56 percent. In Franklin County (Columbus), 1976-1978, when a host of preliminary death certificates were not updated, only 133 of an estimated 215.3 homicides appeared in the ODH mortality files -62 percent. And when we linked the homicides in ODH mortality data, 1979-1988, for the entire state to the preliminary data filed with the National Center of Health Statistics within the eighteen month time limit, we discovered that only 5539 of the 7595 homicides in the ODH data appeared as homicides in the NCHS data -72 percent. An additional 73 deaths listed as homicides in the NCHS data were later reclassified as non-homicides. But 1,983 homicides that appeared in the final ODH mortality data did not appear as homicides in the NCHS data.

What this means, of course, is that scholars will not be able to understand homicide trends accurately without archival research in multiple sources - the kind of research that historians are trained and motivated to do.

I can assure fellow historians of crime that the requisite research is not entirely quantitative or mind-numbing. The case files we have read, thanks to the cooperation of the Cincinnati, Cleveland, and Columbus police departments, are stunning in their detail, and they offer windows not merely into the crimes under investigation, but into the social and material circumstances of people's lives. The case files differ in style from department to department, but each is uniquely helpful, including the transcribed, verbatim transcripts of interviews with witnesses and suspects in

6 The estimated number of homicides was calculated using the "matching list" technique, which in this case matched the ODH list of homicides with the SHR list of homicides. See Eckberg (2001) and Roth (2001) for details of the method. 
Cincinnati, the toxicology tests on victims in Cleveland, and the detailed descriptions of crime scenes in Columbus, which list every stick of furniture, every carpet stain or dirty dish, the brands of liquor and cigarettes, and the shows that were playing on television at the times of the murders. The potential for cultural and anthropological historians to improve understanding of contemporary crime and social conditions are manifold - but only we pitch in and do the work that scholars in other fields have declined to do.

\begin{tabular}{|l|c|c|}
\hline & In NCHS mortality files & \% in NCHS mortality files \\
\hline Casualty & 21 & 0.003 \\
\hline Natural causes & 7 & 0.001 \\
\hline Suicide & 30 & 0.004 \\
\hline Unknown cause & 3 & 0.000 \\
\hline Assault for unknown intent & 12 & 0.002 \\
\hline Homicide & 5539 & 0.729 \\
\hline Missed homicide & 1983 & 0.261 \\
\hline Total homicides & 7595 & \\
\hline
\end{tabular}

The same applies to the study of particular kinds of homicides, such as homicides by law enforcement officers. Today's official databases capture fewer than half of such homicides, even though landmark histories like Marilynn Johnson, Street Justice: A History of Police Violence in New York, demonstrate that police-involved homicides can be studied comprehensively and imaginatively through archival research ${ }^{7}$. The urgency of such work is evident from the information on policeinvolved homicides in the United States that the Guardian, the Washington Post, and the website FiveThirtyEight gathered in 2014 and 2015. The totals are startling: 1,145 confirmed homicides by law enforcement in the United States in 2015. If we adopt a high estimate and assume that there were 800,000 officers patrolling, responding to calls, and making arrests, it means that officers took the lives of civilians in 2015 at a rate of 143 per 100,000 officers: a stunning figure, well above the 5 per 100,000 at which the general population committed homicide ${ }^{8}$.

Again, our preliminary work on the National Homicide Data Improvement Project has yielded important results. In our pilot study of 34 counties in Ohio, 19591988, we found a total of 419 homicides by police officers and 40 by security guards during legal interventions, and 54 homicides of police officers and 11 of security guards during legal interventions. The ratios of homicides to homicide victims are starkly different for police officers and security guards: 10.5 to 1 versus 4.9 to 1 . Our case narratives suggest that security guards are far less likely than police officers to expect lethal assaults from civilians and to expect the need to use deadly force in confrontations with the public. 
The SHRs did not have a separate category in these years for homicides by "legal intervention," but the International Code of Deaths did, so homicides by law enforcement officers and security guards in the line of duty appear in state mortality files. The data on police and security guard involved homicides gathered by the Ohio Department of Health were fairly accurate from 1959-1967. The ODH coded 88 of the 98 of the legal interventions correctly ( 90 percent), and miscoded only one non-legal intervention as a legal intervention. The data are not as accurate, however, after 1967, when the International Codes of Death for legal interventions became more numerous and complicated, and there was no longer a single code for legal interventions adjacent to the codes for other homicides. It is clear from our research that some local medical examiners were baffled by the new, complex coding system, and uncertain whether interventions by security guards should continue to count as "legal interventions." Only one legal intervention was miscoded, but the ODH identified only 285 of the 377 legal interventions from 1968-1988 (76 percent). And the mortality data from the National Center for Health Statistics are much less accurate, because the data gathered from late reporting jurisdictions do not appear. The NCHS data coded accurately only 81 of the 98 legal interventions from 19591967 (82 percent), and only 232 of 377 from 1968-1988 (62 percent).

The Ohio data show that in these years the number of police and security involved homicides (as assailants and as victims) went up and down almost in perfect synchrony with the number of homicides - the same pattern that Roth (2009) identified in earlier periods in American history. The up and down patterns were nearly identical for African American victims and for European American victims in Ohio. Legal interventions and homicides of officers and security guards have followed the same logic (or illogic) as other homicides in American history: when the homicide rate was high, the legal intervention homicide rate was high, because police officers, security guards, and victims were caught up in the same forces driving the homicide rate up throughout the society. And when the homicide rate was low, the same forces drove the legal intervention homicide rate down.

It will be interesting, of course, to see if the same patterns prevail after 1988, but when protocols restricting the use of legal force were put in place in most Ohio jurisdictions in the late 1960s and early 1970s, the number of suspected felons who were shot while trying to flee from officers declined drastically. The percentage of victims killed while trying to flee from police or security guards fell from 39 percent of all legal intervention homicides from 1959-1967, to 29 percent, 1968-1971, to 12 percent, 1972-1988. The proportions were different, however, for black and white victims, once the new protocols were introduced.

\begin{tabular}{|l|l|l|l|}
\hline & White victims & Black victims & All victims \\
\hline $1959-1967$ & 0.37 & 0.41 & 0.39 \\
\hline $1968-1971$ & 0.19 & 0.35 & 0.29 \\
\hline $1972-1988$ & 0.07 & 0.15 & 0.12 \\
\hline
\end{tabular}

It may well be, of course, that black suspected felons have been more likely since the mid-1960s than white suspected felons to flee from police-an argument made forcefully in Alice Goffman's On the Run, an ethnography of an African American 
neighborhood in contemporary Philadelphia ${ }^{9}$. But if that proves not to be the case in the nation as a whole, it would appear that the protocols that have restricted the use of lethal force since the mid-1960s have protected whites more than blacks, particularly in the years in which conflict between African Americans and the police was most intense: 1968-1971. The policies of the late 1950s and early 1960s, which allowed officers to fire at will at fleeing suspects, even if the suspects did not at the time threaten officers or civilians, may ironically have been less racially biased in practice than modern protocols, which ask officers and security guards to stop and think before they fire at a fleeing felon - protocols that could allow conscious or unconscious racial bias to intervene.

\section{BETTER DESCRIPTIONS AND EXPLANATIONS}

I believe that historians of crime also have much to offer criminology when it comes to providing historical perspective on contemporary trends and to confronting the complexity of historical change. For instance, the data on homicide from the Bureau of Vital Statistics - the longest, most reliable official time series available on any type of violent crime show that the "crime drop" of the 1990s in the United States was not really a crime drop. It was an artifact of two competing trends: a long-term decline since the 1970s in homicides of persons ages twenty-five and older, and an abrupt rise and fall of homicides of persons under the age of twenty-five between 1985 and 2000.

The aggregate homicide data give the appearance of a "crime drop" in the 1990s, which followed a sustained rise that began in the $1960 \mathrm{~s}^{10}$. But if we disaggregate homicide rates by age and index those rates to 1959 - the low point in the nation's homicide rate over the past century - it is evident that the aggregate statistics hide important features of the two crime drops that have occurred since the late 1920s. Homicide victimization rates for each age group went down together in unison for all age groups during the decline from 1934 to 1959. Indeed, homicide victimization rates for each age group went up and down together during the entire period from the late 1920s until the mid-1980s - a sign that forces at the aggregate level, such as feelings toward government and society, drove homicide rates ${ }^{11}$. Victimization rates for persons under age 25 went up slightly faster in the 1960s and early 1970s than the rates for persons ages 25 and older, but rates for older Americans largely kept pace. In the mid-1980s, however, victimization rates for older and younger Americans diverged. Rates for persons age 25 and older continued their almost steady decline from the early 1980s to the present (except in Los Angeles, New York City, Baltimore, and the District of Columbia for persons ages 25 to 44, where rates remained high into the early 1990s). But rates for persons under age 25 soared suddenly in the mid1980s and early 1990s (except in Kentucky, West Virginia, northern New England, and the Mountain states, where the rates held steady). Rates for persons under age 25

\footnotetext{
9 Goffman (2014).

10 Graphs that illustrate the statistical trends described in this essay are available through the Historica Violence Database (HVD), as "Figures for Criminologists and Historians of Crime: A Partnership Well Worth Pursuing." https://cjrc.osu.edu/research/interdisciplinary/hvd. See Figure 1(CHC HVD).

11 Roth (2009) and LaFree (1998).
} 
have fallen rapidly since the early 1990s, but they remain well above the indexed rates for victims ages 25 and older. These conflicting trends suggest that the impact of aggregate forces were dampened or overwhelmed from the mid-1980s to $2000^{12}$.

The Vital Statistics of the United States make it possible to view these longterm trends in victimization by gender and race, even though data prior to 1959 are available only for the categories of "white" and "nonwhite." The latter is a rough proxy on the national level for homicide rates for African Americans before 1965, when the Immigration and Nationality Act increased immigration from Asia, Latin America, and the Middle East. The data available since 1959 for persons of other races (including Native Americans and Asian Americans) must be aggregated into broader age groups to yield stable rates, because of the smaller size of each age cohort.

The data for males show that rates moved in unison across age groups into the mid-1980s and tracked closely with feelings towards government and society. The homicide victimization rates for black males and males of "other" races (Asian Americans and Native Americans) peaked during the Nixon presidency in the mid1970s, when distrust of government peaked among racial minorities. Homicide victimization rates peaked for whites during the Carter presidency in 1980, when distrust of government peaked among whites ${ }^{13}$. But beginning in the mid-1980s, the rates diverged widely by age. "Bumps" in homicide rates were experienced by nearly every male age cohort from 1985 through 1994. The bumps are consistent with the rise in disillusionment with government in those years, but they differed radically in magnitude. The bumps for older males are faint echoes of the bumps for younger males. The rates for males ages 10 to 19 peaked for whites at four to six times the rates of 1959, and for blacks at five to six times the rates of 1959. The rates for males of other races are too unstable for persons ages 10 to 14 to allow for comparison, because of the small number of homicides in a given year; but the peak for males ages 15 to 24 was comparable to the peaks for white and blacks males ages 20 to 24 , at two and a half to three times the rates in 1959. Those rates are markedly different from the rates for males ages 25 and older, which despite their slight 1985-1994 "bumps" continued their strong downward trend, which began for whites in the early 1980s and for minorities in the mid-1970s. Thus, the homicide decline for older males began long before the "crime drop" of the 1990s.

The victimization trends for older females were similar to those for older males, but subtly different for younger persons ${ }^{14}$. The indexed rates for white females under age 25 diverged sharply from the rates of older white females beginning in the mid1960s to the 1970s - much earlier than the rates diverged for younger males. The indexed rates for black females reveal that the surge in youth homicides in the late 1980 s and early 1990s was confined largely to ages 10 to 14 . And the indexed rates show that the surge in youth homicides did not affect Asian American or Native American females at all. The trends in homicides of younger females were thus more varied and complex than those of younger males and will require considerable research to sort out. But the trends for older females were identical to those for older males.

Why did victimization rates for older Americans begin to trend downward more than a decade before the alleged "crime drop" of the mid- and late 1990s?

\footnotetext{
12 See Figures 2 through 6 (CHC HVD).

13 (Roth 2009: 452-464). See Figures 7 through 9 (CHC HVD).

14 See Figures 10 through 12 (CHC HVD).
} 
What forces dampened the effect of feelings toward government and society on their homicide rates, and turned the decline in minority distrust of government after President Nixon's resignation and in white distrust of government after President Reagan's election into a sustained decline in violent crime? That long-term decline was evident not only in homicide rates, but in rates of armed robbery, sexual assault, and aggravated assault, as reported by the National Crime Victimization Survey, which has surveyed large samples of Americans twice a year since $1972^{15}$.

Many forces may have been at work behind that long decline in violence against Americans ages 25 and older, but it will require the work of historians to sort them out. Gun ownership has declined dramatically in the United States since 1973, but in a partisan way. In that year, half of all Republicans, Democrats, and Independents had a firearm in the home. Today, half of all Republicans still do, but only a third of Independents and a fifth of Democrats, according to the General Social Survey ${ }^{16}$. Would it be possible to estimate gun ownership on the local level and sort out whether the steepest declines in homicide and armed robbery correlate with the steepest drops in gun ownership? And if that were to prove to be the case, what would the mechanism be? Would it be the lack of firearms or the feelings and beliefs behind the decision to disarm? A rejection of violence in all its forms? An embrace of the politics of tolerance and inclusion? And what about changes in the number and tactics of the police? Were they more effective for some reason in protecting older Americans than younger Americans? Was there, in short, a social geography of effective policing, especially as middle class and wealthy neighborhoods ramped up public and private security?

Scholars should also consider the possibility that mass incarceration may have disrupted the historic pattern, if only by saving the lives of convicts who would otherwise have been killed on the streets. Mass incarceration, particularly of nonviolent offenders, the mentally ill, and the drug dependent, has done untold damage to American society, but the correlations between mass incarceration and the homicide rate for Americans age 25 and older are startling ${ }^{17}$. For white males from 1974 to 2010 (a category which includes most Hispanics as well as non-Hispanic whites), r-squares are consistently above 0.74 for persons ages 25 to 74 . That does not mean, of course, that the

15 Lauritsen and Cork (2016); Lauritsen et al. (2016); Berg and Lauritsen (2016); Lauritsen and Rezey (2013).

16 "Party Identity in a Gun Cabinet," FiveThirtyEight, 18 December 2012, https://fivethirtyeight.com/ features/party-identity-in-a-gun-cabinet/.

17 On the incarceration boom and its impact, see Gottshalk $(2006,2015)$ and Travis et al. (2014). The data on incarceration rates in prisons, jails, and juvenile institutions (both public and private) are calculated from the Sourcebook of Criminal Justice Statistics (1973-present), and from Surveys of Jail Inmates $(1972,1978,1983,1989,1996$, and 2002) and Surveys of Inmates of State and Federal Correctional Facilities (1974, 1979, 1986, 1991, 1997, and 2004). All of these statistics were compiled by the Bureau of Justice Statistics. Strong assumptions must be made to arrive at estimates of the gender, age, and racial composition of the inmate populations, 1) because the data on inmates in juvenile justice institutions were not cross tabulated, 2) because no survey of inmates in federal correctional facilities was conducted before 1991, and 3) because the results of more recent surveys of inmates in state or federal correctional facilities are not yet available. The analysis here assumes that the distributions by age and race were identical for male and female juveniles, and it extrapolates backward and forward to determine the age, gender, and racial distributions for prisoners and jail inmates, which did change over time. Unfortunately, given the lack of adequate data, that is the best we can do at present. 
slopes are steep in substantive terms. The drops in homicide rates per 100,000 persons per year are small relative to increases in incarceration rates per 100,000 persons, although the drops increase with age. Imprisoning an additional 100 white males per 100,000 correlates with a 0.5 drop per 100,000 in homicide victimization rates for ages 25 to 34, 0.7 for ages 35 to $44,1.1$ for ages 45 to $54,1.6$ for ages 55 to 64 , and 3.5 for ages 65 to $74^{18}$. But given the magnitude of the increase in incarceration from 1974 to 2010, which went, for example, for white males ages 35 to 44 from roughly 270 per 100,000 to over 1,500, and for white males ages 25 to 34 from 400 to 1700 , the modest decreases in homicide associated with each additional 100 persons per 100,000 incarcerated means that the rise in incarceration could "explain" statistically between half and three-quarters of the homicide drop for the white male age cohorts from ages 25 to 34 to ages 65 to 74 .

For black males age 25 and older, the results are similar. R-squares are consistently above 0.72 from ages 25 to 34 through ages 55 to 64 , although the $\mathrm{r}^{2}$ drops to 0.50 for ages 65 to 74, because the incarceration rates for older blacks fell by a quarter after 1990. Imprisoning an additional 100 black males per 100,000 correlates with a 0.8 drop per 100,000 in homicide for ages 25 to $34,1.1$ for ages 35 to $44,1.6$ for ages 45 to $54,3.7$ for ages 55 to 64 , and 9.1 for ages 65 to 74 . Again, given the startling magnitude of the increase in incarceration from 1974 to 2010, which went for example for black males ages 35 to 44 from roughly 1500 per 100,000 to 8,900 , and for black males ages 25 to 34 from 3,100 to 10,500, the modest decreases in homicide associated with each additional 100 persons per 100,000 incarcerated means that the rise in incarceration could "explain" statistically between half and four-fifths of the homicide drop for the black male age cohorts from ages 25 to 34 to ages 65 to 74. The correlations between incarceration and homicide victimization are not as consistently strong for black females age 25 and older as for males, but they too show a strong inverse relationship, as do the correlations for white females age 25 and older, which are as strong as those for white males ${ }^{19}$. Even with these strong correlations at the national level, however, it will require the work of historians to determine on the local level whether higher incarceration rates led to the steeper drops in homicide and other violent crimes.

Finally, what of the sudden rise and fall in the rate of youth homicides, 19852000? It has become commonplace to cite the "crack epidemic," which took hold in the mid-1980s. Crack entrepreneurs certainly relied on younger dealers and couriers to handle the trade, especially teens who were not old enough to be tried as adults if they were caught. But there are many reasons for historians to be skeptical of such a straightforward explanation. For one, the crack epidemic did not end in the mid- and late-1990s, when the youth homicide rate dropped. Hospital admissions and crack overdose deaths held steady at peak levels into the early 21 st century, and the heroin and opioid epidemics had just begun to take off ${ }^{20}$. And why would the crack trade be so much more violent than previous drug trades? Here again, cultural historians would have a great deal to contribute. Is it a coincidence that the youth homicide rate went

18 Tables that illustrate the statistical trends described in this essay are available through the Historical Violence Database (HVD), a "Tables for Criminologists and Historians of Crime: A Partnership Well Worth Pursuing." https://cjrc.osu.edu/research/interdisciplinary/hvd. See Table 1 (CHC HVD).

19 See Tables 2 through 4 (CHC HVD).

20 Fryer et al. (2013: 1654). 
up and down with the popularity of the most virulent, misogynistic, alienated gangsta rappers, from Schooly D and Ice T to N.W.A.? With sales nationwide of Oakland Raiders gear, even though the Raiders were a pretty average football team in the late 1980s and early 1990s, when sales of their gear peaked? With surveys that revealed a nationwide rise and decline in distrust of government and public officials over those same sixteen years ${ }^{21}$ ? Why did young men in areas of concentrated poverty, come together across racial divides to embrace a subversive, violent lifestyle in the mid1980s, and reject it just as decisively in the mid- and late-1990s? These are questions that only historians of crime can answer through oral history and archival research.

I must confess in closing that my frustration as the lone historian on the Roundtable on Crime Trends peaked over just this issue: description and explanation. An economist on the Roundtable pointed out, correctly, that the suicide rate for young Americans declined in the mid- and late-1990s at the same time their homicide rate declined. He thought that the decline in suicide might reflect changes in emotion and experience that contributed to the decline in youth violence. In response, I referred to a graph I had made of suicides rates in the United States, 1928-201222. I pointed out that the graph of suicide rates looked wholly different from the graph of homicide rates, and that the long-term correlation between homicide rates and suicide rates for various age groups was pretty much nil. And although the suicide rate for young people under age 25 did drop, it was still four times higher than it was in the 1950 s and early 1960s, the last time the national homicide rate fell to 5 per 100,000 per year, so it was difficult to imagine that young people had regained the positive outlook toward life they had had in the postwar era. And although the suicide rate for persons ages $15-19$ did rise from the mid-1980s to the early 1990s, it had been rising steadily since the late 1950s, long before the surge in youth homicides; and the suicide rate for persons ages 20-24 had been declining since the mid-1970s, a decline that apparently had no deterrent effect when the youth homicide boom occurred. The economist's response: "We agreed that we would study the crime drop in the 1990s." So much for the importance of history!

None of this is to say that historians of crime should turn away from the fascinating work they are doing on crime in the medieval and early modern eras, on the nineteenth century, or the early twentieth century. Their work has revealed deep patterns in the history of crime that could never be seen by scholars who work only on contemporary problems. But given the difficulty of describing and explaining contemporary trends, I believe historians of crime have much to contribute to the study of the recent past and to contemporary debates about the causes and cures for violent crime.

\author{
Randolph Roth \\ Department of History \\ Ohio State University \\ Columbus OH, USA \\ Roth.5@osu.edu
}

\footnotetext{
21 Wilson et al. (2015); and LaFree (1998). The pioneers of gangsta rap produced their first hits in 1985 and 1986, the years when the surge in youth homicides began. See Schooly D, "P.S.K." (1985) and Ice-T, "6 in the Morning" (1986).

22 See Figure 13 (CHC HVD).
} 


\section{BIBLIOGRAPHY}

Azrael, D, Barber, C. and Mercy, J. (2001) Linking Data to Save Lives: Recent Progress in Establishing a National Death Reporting System, Harvard Health Policy Review, 2, p. $38-42$.

Berg, M.T. and Lauritsen, J.L. (2016) Telling a Similar Story Twice? NCVS/UCR Convergence in Serious Violent Crime in Rural, Suburban, and Urban Places (1973-2010), Journal of Quantitative Criminology, 32, p. 61-87.

Eckberg, D.L. (2001) Stalking the Elusive Homicide: A Capture-Recapture Approach to the Estimation of Post-Reconstruction South Carolina Killings, Social Science History, 25, p.67-91.

Fox, J.A. and Swatt, M.L. (2009) Uniform Crime Reports [United States]: Supplementary Homicide Reports with Multiple Imputation, Cumulative Files 1976-2007 [Computer file]. ICPSR24801-v1, Ann Arbor, Michigan, Inter-university Consortium for Political and Social Research [distributor], 2009-02-24, doi:10.3886/ICPSR24801.

Fryer, R.G., Jr., Heaton, P.S., Levitt, S.D., and Murphy, K.M. (2013) Measuring Crack Cocaine and Its Impact, Economic Inquiry, 51, p. 1651-1681.

Goffman, A. (2014) On the Run: Fugitive Life in an American City, Chicago: University of Chicago Press.

Gottschalk, M. (2006) The Prison and the Gallows: The Politics of Mass Incarceration in America, New York: Cambridge University Press.

Gottschalk, M. (2015) Caught: The Prison State and the Lockdown of American Politics, Princeton: Princeton University Press.

Johnson, M. S. (2003) Street Justice: A History of Police Violence in New York City, Boston, Beacon Press.

Karch, D.L. and Logan, J.E. (2008) Homicide Incidents in the National Violent Death Reporting System and Data Consistency in Multiple Source Documents: Findings From 2003-2004, Homicide Studies, 12, p. 264-276.

LaFree, G. (1998) Losing Legitimacy: Street Crime and the Decline of Social Institutions, Boulder, Co:, Westview Press.

Lauritsen, J.L. and Cork, D.L. (Eds.) (2016) Modernizing Crime Statistics - Report 1: Defining and Classifying Crime, Panel on Modernizing the Nation's Crime Statistics, Committee on National Statistics and Committee on Law and Justice, Washington, D.C., The National Academies Press, http://www.nap.edu/catalog/23492/modernizing-crime-statistics-report-1definingandclassifying-crime.

Lauritsen, J.L. and Rezey, M.L. (2013) Measuring the Prevalence of Crime with the National Crime Victimization Survey, Washington, D.C.: U.S. Department of Justice, Bureau of Justice Statistics, NCJ241656.

Lauritsen, J.L., Rezey, M.L, and Heimer, K. (2016) When Choice of Data Matters: Analyses of U.S. Crime Trends, 1973-2012, Journal of Quantitative Criminology, 32, p. 335-355.

Loftin, C. and McDowall, D. (2010) The Use of Official Records to Measure Crime and Delinquency, Journal of Quantitative Criminology, 26, p. 527-532.

Loftin, C., McDowall, D. and Fetze, M. (2008) A Comparison of SHR and Vital Statistics Homicide Estimates for U.S. Cities, Journal of Contemporary Criminal Justice, 24, p. 4-17. 
Logan, J.E., Karch, D.L, and Crosby, A.E. (2009) Reducing “Unknown” Data in Violent Death Surveillance: A Study of Death Certificates, Coroner/Medical Examiner and Police Reports From the National Violent Death Reporting System, 2003-2004, Homicide Studies, 13, p. 385-397.

Maltz, M.D. (1999) Bridging Gaps in Police Crime Data, Bureau of Justice Statistics Fellows Program Discussion Paper, Document No. NCJ 176365, Washington, DC: Bureau of Justice Statistics.

Maltz, M.D. (2006) Analysis of Missingness in UCR Crime Data, Report to the National Institute of Justice under Award No. 2004-IJ-CX-0083, Document No. 21543, Washington, D.C.: National Criminal Justice Reference Service.

Riedel, M. and Regoeczi, W.C. (2006) A Case-by-Case Comparison of the Classification of Law Enforcement and Vital Statistics Data on Homicide, Criminal Justice Policy Review, 17 , p. 61-82.

Rokaw, W.M., Mercy, J.A, and Smith, J.C. (1990) Comparing Death Certificate Data with FBI Crime Reporting Statistics on U.S. Homicides, Public Health Reports, 105, p. 447-455.

Roth, R. (2001) Child Murder in New England, Social Science History, 25, p. 101-147.

Roth, R. (2009) American Homicide, Cambridge: Belknap Press of Harvard University Press.

Shields, R.T. and Ward, B.W. (2008) Comparison of the National Violent Death Reporting System and Supplementary Homicide Report: Potential Benefits of Integration, Justice Research and Policy, 10, p. 67-97.

Travis, J., Western, B. and Redburn, S. (Eds.) (2014) The Growth of Incarceration in the United States, Washington, D.C.: National Academies Press.

Van Court, J. and Trent, R.B. (2004) Why Didn't We Get Them All?: Analyzing Unlinked Records in California's Linked Homicide File, Homicide Studies, 8, p. 311-321.

Wiersema, B., Loftin, C. and McDowall, D. (2000) A Comparison of Supplementary Homicide Reports and National Vital Statistics System Homicides Estimates for U.S. Counties, Homicide Studies, 4, p. 317-340.

Wilson, C., Feifer, J. and Faraone, C. (2015) N.W.A.: The Legacy, Maxim, p. 34-35.

Zimring, F.E. (2017) When Police Kill, Cambridge: Harvard University Press. 